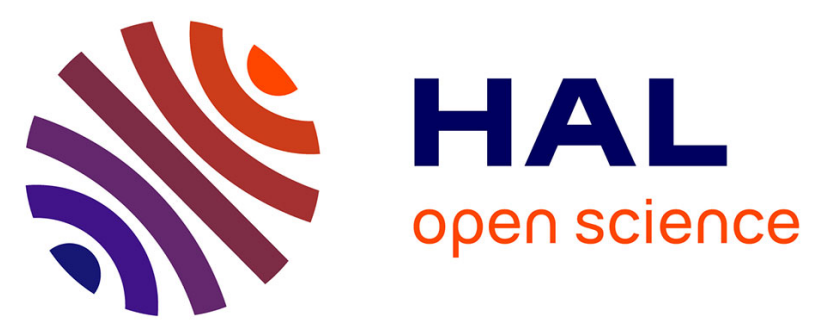

\title{
DETERMINATION OF THE V4-CENTER STRUCTURE IN KBr CRYSTAL BY MEANS OF DOUBLE ALIGNMENT CHANNELING TECHNIQUE
}

Y. Mitsushima, K. Morita, N. Matsunami, N. Itoh

\section{- To cite this version:}

Y. Mitsushima, K. Morita, N. Matsunami, N. Itoh. DETERMINATION OF THE V4-CENTER STRUCTURE IN KBr CRYSTAL BY MEANS OF DOUBLE ALIGNMENT CHANNELING TECHNIQUE. Journal de Physique Colloques, 1976, 37 (C7), pp.C7-95-C7-100. 10.1051/jphyscol:1976714 . jpa-00216864

\section{HAL Id: jpa-00216864 https://hal.science/jpa-00216864}

Submitted on 1 Jan 1976

HAL is a multi-disciplinary open access archive for the deposit and dissemination of scientific research documents, whether they are published or not. The documents may come from teaching and research institutions in France or abroad, or from public or private research centers.
L'archive ouverte pluridisciplinaire HAL, est destinée au dépôt et à la diffusion de documents scientifiques de niveau recherche, publiés ou non, émanant des établissements d'enseignement et de recherche français ou étrangers, des laboratoires publics ou privés. 


\title{
DETERMINATION OF THE $\mathrm{V}_{4}$-CENTER STRUCTURE IN KBr CRYSTAL BY MEANS OF DOUBLE ALIGNMENT CHANNELING TECHNIQUE
}

\author{
Y. MITSUSHIMA, K. MORITA, N. MATSUNAMI and N. ITOH
}

Department of Nuclear Engineering, Nagoya University, Nagoya, Japan

\begin{abstract}
Résumé. - Nous avons déterminé la position des atomes interstitiels impliqué dans les centres $\mathrm{V}_{4}$ de cristaux de $\mathrm{KBr}$ par la technique de channeling par alignement double. Une mesure d'abosrption optique d'un cristal de $\mathrm{KBr}$ irradié par des protons ou des atomes d'hélium à la température de l'azote liquide nous a assurés que la courbe $\mathrm{V}_{4}$ est un défaut interstitiel principalement produit par le rayonnement. Un faisceau bien collimaté d'ions $\mathrm{He}^{+}$, de $1,25 \mathrm{MeV}$, a été envoyé parallèlement à la direction [110] des cristaux de $\mathrm{KBr}$. La dépendance angulaire de la production d'ions hélium ren-

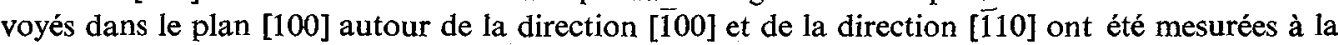
température de l'azote liquide et possèdent respectivement un pic large au centre et un pic double. La méthode de Monte Carlo a été employée pour calculer la dépendance angulaire de la production d'atomes renvoyés pour différentes positions interstitielles dans le channeling en double alignement. La comparaison entre les résultats expérimentaux et calculés indique qu'un atome de Br interstitiel du centre $V_{4}$ occupe une position proche du centre du corps. Des expériences d'optique et de channeling, nous avons conclu que le centre $V_{4}$ est une molécule neutre d'halogène dont chaque atome est situé dans la position décrite ci-dessus.

Abstract. - The position of interstitial atoms involved in the $\mathrm{V}_{4}$-center in $\mathrm{KBr}$ crystal has been determined with the double alignment channeling technique. An optical absorption measurement of $\mathrm{KBr}$ crystal irradiated with protons or heliums at liquid nitrogen temperature assured that the $\mathrm{V}_{4}$-center is the predominant radiation-induced interstitial defect. $\mathrm{A}$ well collimated beam of $1.25 \mathrm{MeV} \mathrm{He}$ ions was incident parallel to the [110] direction of $\mathrm{KBr}$ crystals. Angular dependence of the yield of the backscattered helium ions in the (100) plane around the [100] direction and the $[\overline{1} 10]$ direction was measured at liquid nitrogen temperature and found to have a broad peak at the center and a double peak, respectively. The Monte Carlo method was employed to calculate the angular dependence of the backscattering yield for several interstitial positions in the double alignment channeling. Comparison between the experimental and calculated results indicates that an interstitial $\mathrm{Br}$ atom of the $\mathrm{V}_{4-\mathrm{center}}$ occupies a position near the body center. From the optical and channeling experiments, it was concluded that the $\mathrm{V}_{4}$-center is a neutral halogen molecule, each atom of which is located at the position described above.
\end{abstract}

1. Introduction. - It is well known that X-ray irradiation or electron irradiation of alkali halides produces halogen Frenkel pairs [1]. At liquid helium temperature an $\mathrm{F}$-center and an $\mathrm{H}$-center constitute a Frenkel pair. The F-center is an electron trapped by a halogen ion vacancy and the $\mathrm{H}$-center is an interstitial neutral halogen atom which forms an $\mathrm{X}_{2}^{-}$molecule at an anion site [2]. The $\mathrm{H}$-centers are unstable at liquid nitrogen temperature, where a $\mathrm{V}_{4}$-center is the complementary pair of the F-center [3]. The $\mathrm{V}_{4}$-center is known to comprise two interstitial neutral halogen atoms and to have a molecular symmetry axis along a $<100\rangle$ direction. Its structure, however, has not been definitely established yet. The EPR technique, which has been frequently used to study color centers, cannot be applied to determine its structure owing to its diamagnetic nature.

Theoretical works on the di-interstitial centers in alkali halides have been made by several authors.
White et al. [4] have calculated the energy required to place a $\mathrm{Cl}_{2}$ molecule in a $\mathrm{NaCl}$ lattice, each $\mathrm{Cl}$ atom being situated in the proximity of the body center of the small cube (one eighth of the unit cell). On the other hand, Catlow et al. [5] compared the energy of various configurations of the di-interstitials in $\mathrm{NaCl}$ and found that the $\mathrm{Cl}_{3}^{-}$molecule at an anion site with a $\langle 111\rangle$ orientation is more stable than the interstitial $\mathrm{Cl}_{2}$ molecule described above.

The channeling technique has been applied to determine the location of the interstitials in crystal lattices $[6,7]$. Single alignment channeling technique has been widely used to determine the impurity location : the incident beam is scanned around a major crystal axis and the particles scattered into a random direction are counted. This technique cannot be used to locate the self-interstitial atoms since the particles scattered by the regular lattice atoms are usually more numerous than those scattered by the interstitial 
atoms. Double alignment channeling technique [8-10], in which both the incident and outgoing beams are aligned simultaneously to major axes, reduces the yield from the regular lattice atoms to $\sim 0.1 \%$ of the random yield. Therefore, in double alignment channeling experiments the scattering yield from interstitials at a concentration of $10^{-3}$ is comparable with that from regular lattice atoms. Appleton et al. [8] made investigations of interstitial $\mathrm{Zn}$ concentration in additively colored $\mathrm{Z}_{\mathfrak{n O}}$. Morita et al. [10] measured the dependence of the intensity of the backscattered particles (yield profile) into a planar channel on the angle of deviation from a certain crystal axis of irradiated silicon crystals. They also calculated [11] the yield profile for the silicon atom located at various positions in the Si-lattice with the Monte Carlo computer simulation. From the comparison between the experimental and calculated yield profiles, the location of the interstitial silicon atoms has been determined.

The purpose of the present paper is to determine the location of the interstitial halogen atoms in the $V_{4}$ center by means of the double alignment channeling technique. The optical absorption of $\mathrm{KBr}$ crystals irradiated with $\mathrm{H}^{+}, \mathrm{H}_{2}^{+}$or $\mathrm{He}^{+}$ions was measured at liquid nitrogen temperature and it is confirmed that the interstitial defect produced predominantly is the $\mathrm{V}_{4}$-center. The backscattering yield profiles in double alignment were measured and compared with the yield profiles for various interstitial sites calculated with the Monte Carlo method. The location of the atoms of the $\mathrm{V}_{4}$-center was determined.

2. Experimental procedure. - Pure $\mathrm{KBr}$ crystals, which were obtained from the Harshaw Chemical Company, were cleaved just before irradiation and mounted on a copper disc which was firmly held on a goniometer placed in a target chamber. The goniometer assembly can be rotated around the vertical (tilt angle) and holizontal (azimuthal angle) axes. The specimens were irradiated with $\mathrm{H}^{+}, \mathrm{H}_{2}^{+}$or $\mathrm{He}^{+}$ beams, which were generated from a Van de Graaff accelerator at Nagoya University. The irradiation and measurements were made at liquid nitrogen temperature. The pressure of the target chamber was about $3 \times 10^{-6}$ torr.

After bombardment of $1.5 \mathrm{MeV} \mathrm{H}_{2}^{+}$or $\mathrm{He}^{+}$particles on a specimen with a beam current of around $60 \mathrm{nA} / \mathrm{cm}^{2}$, the optical absorption was measured with a conventional technique. The dichroism of the $\mathrm{V}_{4}$ center was determined in the following way. After bombardment the specimens were bleached with U. V. radiation polarized along the [001] axis or [011] axis and the absorption was measured with radiation polarized parallel and perpendicular to the bleaching radiation. The bleaching light was obtained from a mercury lamp through a UV-D25 filter (Toshiba).

The $\mathrm{He}^{+}$beams of $1.25 \mathrm{MeV}$ were collimated to an angular spread less than $1.3 \times 10^{-3}$ rad by two slits of $2 \mathrm{~mm}$ and $0.3 \mathrm{~mm}$ in diameter. The backscattered He ions were detected with plastic films (Cellulose Nitrate of $\sim 15 \mu \mathrm{m}$ in thickness) placed at the direction of the $[\overline{100}]$ and $[\overline{1} 10]$ axes. This technique has an advantage that the fluctuation of the incident beam current during the measurement does not affect the obtained yield profile. The distances from the crystal to the detector placed at the $[\overline{100}]$ and the $[\overline{1} 10]$ directions were $12 \mathrm{~cm}$ and $20 \mathrm{~cm}$, respectively.

After the exposure, the film was etched for $10 \sim 20$ minutes in $6 \mathrm{~N} \mathrm{NaOH}$ maintained at $\sim 60^{\circ} \mathrm{C}$. The particle tracks on the etched film were counted with a conventional light microscope combined with the automatic television counter. The spatial distributions of particle tracks on the film were obtained from the counts in the area of $0.1 \times 0.13 \mathrm{~mm}^{2}$ and of $0.2 \times 0.26 \mathrm{~mm}^{2}$ for the [100] and [110] axes, respectively. From the obtained spatial distributions of the particle tracks, the dependence of the scattering yield on the tilting angle in the (100) plane from both axes were deduced.

The optimum number of the tracks on the films is $\sim 10^{4} \mathrm{~mm}^{-2}$. To monitor the number of the particles being bombarded on the film, a Si-surface-barrier detector with a sensitive area of $25 \mathrm{~mm}^{2}$ and apart from the target crystal by $7 \mathrm{~cm}$ was used. The discrimination level of the counting system was set at the threshold energy, $400 \mathrm{keV}$, of the plastic film for detecting $\mathrm{He}^{+}$ions. The bombardment was continued until the number of the tracks on the films reaches the optimum value. The beam current was $1.5 \mu \mathrm{A} / \mathrm{cm}^{2}$.

3. Experimental results. - The change in the optical absorption spectrum of $\mathrm{KBr}$ crystal by irradiation with $\mathrm{H}_{2}^{+}$at a dose of $5 \times 10^{13} \mathrm{~cm}^{-2}$ is shown by the solid line in figure 1 . The broken line is the optical absorption spectrum of $\mathrm{KBr}$ crystal irradiated with $\mathrm{X}$-rays at liquid nitrogen temperature. The two

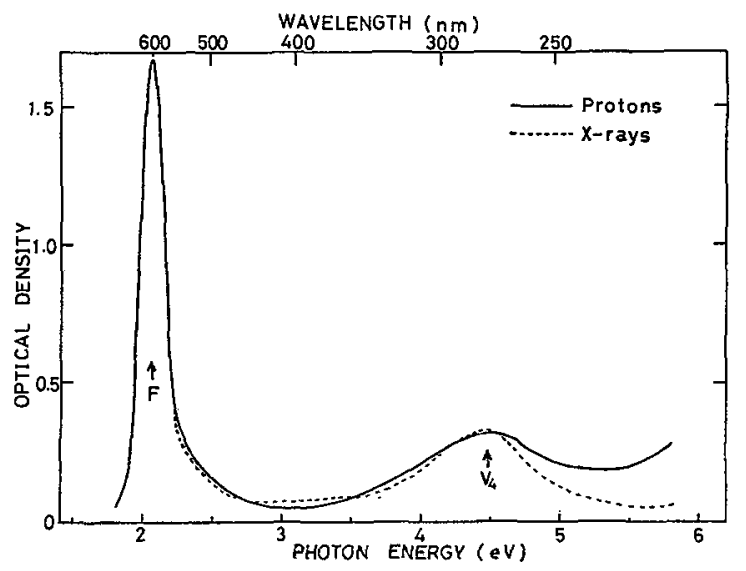

FIG. 1. - Optical absorption spectra of $\mathrm{KBr}$ irradiated with 1.5 $\mathrm{MeV} \mathrm{H}_{2}^{+}$beams (solid line) and $\mathrm{X}$-rays (broken line) at liquid nitrogen temperature. Two curves were normalized at the peak height of the $\mathrm{F}$ band. 
curves were normalized at the peak height of the $F$ band. The comparison between two spectra shows that the peak heights of the $\mathrm{V}_{4}$-band agree each other, although in the case of the $\mathrm{H}_{2}^{+}$irradiation background in the high energy side of the $V_{4}$-band is raised. This shift of the background may be ascribed to the surface defects due to sputtering by the $\mathrm{H}_{2}^{+}$ bombardment. The average concentration of the $F$ center over the range $14.1 \mu \mathrm{m}$ of $750 \mathrm{keV} \mathrm{H}^{+}$was evaluated to be $1.5 \times 10^{-3}$ with the value 0.8 of the oscillator strength of the F-center. Essentially the same absorption spectra were obtained by $\mathrm{He}^{+}$irradiation.

The specimens irradiated with $\mathrm{He}^{+}$ions at a dose of $8 \times 10^{12} \mathrm{~cm}^{-2}$ were bleached with light polarized along [001] and [011]. The difference in the concentrations of the $\mathrm{V}_{4}$-center oriented parallel and perpendicular to the bleaching light was measured as a function of bleaching time. The difference divided by the initial concentration of the $\mathrm{V}_{4}$-center is plotted in figure 2. It is seen that the dichroism is produced only by the [001] bleaching, indicating that the symmetry axis of the $V_{4}$-center is $\langle 100\rangle$. These results agree with the symmetry property of the $V_{4}$-center produced by X-ray irradiation [12].

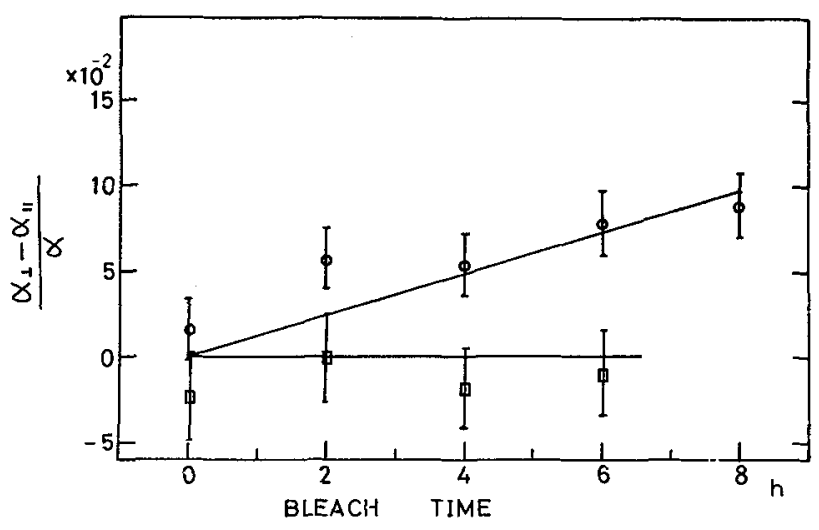

Fig. 2. - Dependence of the degree of polarization in the absorption coefficients of the $\mathrm{V}_{4}$-band incident along [100] and polarized along [001] $(O)$ and along [011] ( $\square$ ).

The backscattering yield profiles around the [100] and [110] directions of irradiated $\mathrm{KBr}$ are shown in figure 3. The abscissa is the tilting angle or the detector angle within the $\{\overline{1} 10\}$-plane. The tilting angle is the angle between the axial direction and the direction of the outgoing beam reaching at a given detector position. The detector angle is divided by the halfangle $\psi_{1 / 2}$, which was calculated with Andersen's procedure [13] to be $0.011 \mathrm{rad}$ and $0.009 \mathrm{rad}$ for the [100] and [ $\overline{1} 10]$ directions, respectively. The yield profile around the [ī00] direction shows a broad peak at the center and around the [110] direction shows a small double peak at $\psi / \psi_{1 / 2}=0.3$. These results show that the interstitial atoms occupy the mid-chan-

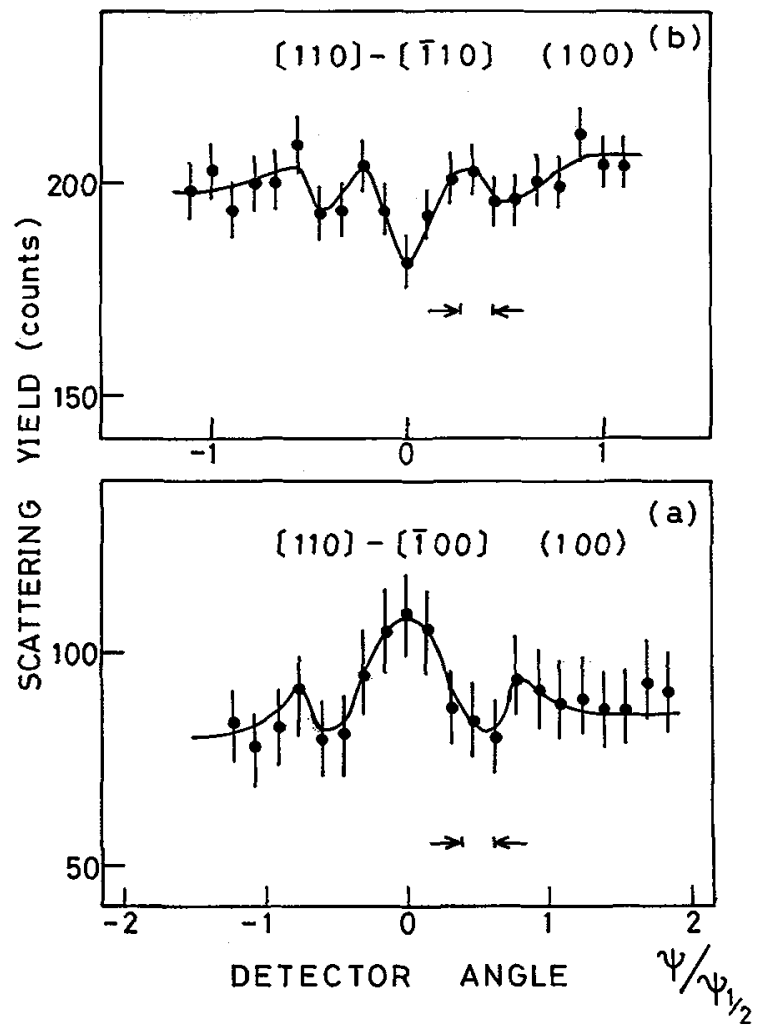

FiG. 3. - Experimental backscattering yield profile in a (100) tilt plane of the helium ions from a radiation damaged $\mathrm{KB} \mu$ crystal at liquid nitrogen temperature. The direction of incidence is [110] and the abscissa is the angle between the ougoing direc-

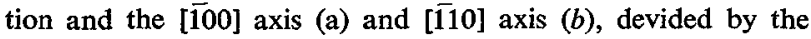
half angle $\psi_{1 / 2}$ of the $<100>$ axis. Incident energy is $1.25 \mathrm{MeV}$ and the width marked by arrows in the figure shows the angular resolution.

nel position in a $<100>$ channel and do not occupy the mid-channel position in a $\langle 110\rangle$ channel.

4. Discussions. - 4.1 Calculation of BaCKscatTERING YIELD PROFILE. - From the single alignment, the backscattering yield from an atom at a given lattice position is known to be equal to the average flux density of channeled particles with a weight of the probability density of thermal vibration. The probability that a scattered atom emerges out from the crystal is also given by a similar average flux density in the outgoing channel. Therefore the scattering yield for the double alignment may be calculated by multiplying the average flux densities at the defect position in the incoming and outgoing channels.

The channeled particles distributions at a depth of 1000 layers in a $\mathrm{KBr}$ lattice at $77 \mathrm{~K}$ were calculated with the Monte Carlo method for $1.25 \mathrm{MeV} \mathrm{He}^{+}$ ions incident in an angular range of 0 to $0.022 \mathrm{rad}$ around $\mathrm{a}<100>$ axis and 0 to $0.018 \mathrm{rad}$ around a $<110>$ axis, the plane of incidence always being a (100) plane. The method of calculation used here was the same as that presented by Morita [11]. With the flux distributions obtained from the calculations, the 
relative double alignment backscattering yield by Br atoms placed on the regular lattice position, the face-centered interstitial position and the bodycentered interstitial position were calculated. The incident direction was $a<110>$ axis and the outgoing directions were $\langle 110\rangle$ and $\langle 100\rangle$ axes. Figure 4 shows the results from the face-centered atoms and the body-centered atoms for the outgoing direction of $\langle 100\rangle$ and $\langle 110\rangle$. In this figure $\psi / \psi_{1 / 2}=0$ represents a $<110>$ axial direction, whereas the plateau at $\psi / \psi_{1 / 2}>1.5$ represents the scattering into the $(100)$ plane. The relative backscattering yield profiles from the regular lattice atoms show monotonous dips.

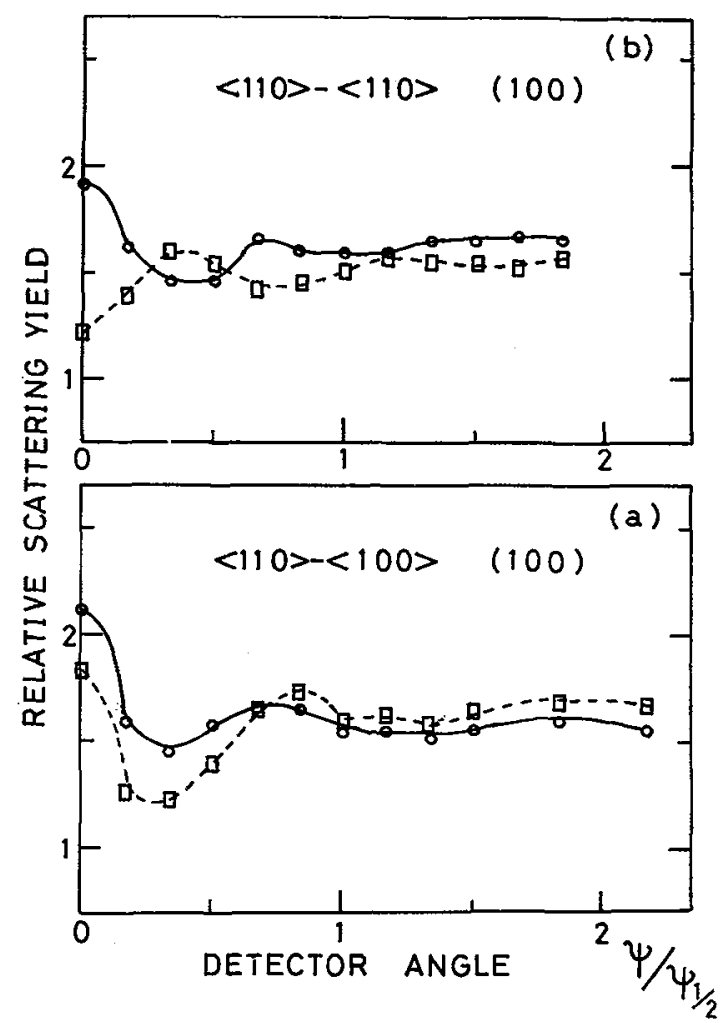

Fig. 4. - Angular dependence of the calculated relative scattering yield of helium ions backscattered from body-centered atoms (dashed line) and face-centered atoms (solid line) in the double alignment channeling. The incident channeling direction is $\langle 110\rangle$ and outgoing direction is tilt in the (100) plane from the $\langle 100\rangle$ axis $(a)$ and the $\langle 110\rangle$ axis $(b)$.

The relative scattering yield $R$ from a crystal containing defects may be calculated by superposition of the yield $R_{1}$ from the interstitial atoms on the yield $R_{\mathrm{L}}$ from the atoms in the regular lattice sites;

$$
R=c R_{\mathrm{I}}+R_{L^{\prime}}
$$

where $c$ is the fractional concentration of the interstitial atoms.

4.2 DiscusSION OF THE EXPERIMENTAL RESULTS. From the optical experiments, it was confirmed that the irradiation of $\mathrm{KBr}$ crystals with $\mathrm{H}^{+}$and $\mathrm{He}^{+}$ at liquid nitrogen temperature produces the F-center and the $V_{4}$-center and that the produced $V_{4}$-center has $a<100>$ symmetry axis. Since the ratio of the height of the $V_{4}$-band to that of the F-band is the same for charged particles and $X$-rays irradiation, one may conclude that no other interstitials than the $V_{4}$ center are produced by particle irradiation. The distortion of the lattice by the F-center may be so small [14] that the channeled particles will not be scattered. Therefore the backscattering yield profiles around the major axes may reflect the location of the interstitial atoms of the $\mathrm{V}_{4}$-center. In view of the calculated results, the existence of the peak at the [100] direction and its absence at the [ $[\overline{1} 10]$ direction in the experimental yield profiles lead to a conclusion that the interstitials of the $\mathrm{V}_{4}$-center are located near the body center. As seen from figure 3, a doublepeak is observed at $\psi / \psi_{1 / 2}=0.3$ for the outgoing direction of [110]. A similar peak is also seen at $\psi / \psi_{1 / 2}=0.3$ in the calculated result for the bodycentered position. Calculations were also made for several interstitial positions and it turns out that the peak disappears when the interstitial is deviated by a 1/8 of the lattice constant from the body center. The deviation of the interstitial position by $1 / 12$ of the lattice constant from the body center does not affect the yield profile appreciably. Thus it is concluded that the position of the interstitial halogen of the $\mathrm{V}_{4}$ center is within a $1 / 8$ of the lattice constant from the body-centered position.

It has been shown [15] that the production of the Frenkel defects is saturated at a concentration of around $5 \times 10^{-3}$. The relative yield profile of the $<100\rangle$ outgoing direction for $\mathrm{KBr}$ crystal including body-centered interstitials at a fractional concentrations of $5 \times 10^{-3}$ were calculated according to eq. (1). The calculated yield profile and the experimental profile are shown in figure 5 , where the values of the yield are normalized by the height of the peak. The calculated yield profile (a) shows a rapid rise towards the planar direction. It is seen in figure 5 that the experimental yield at the planar direction is smaller than the calculated yield by a factor of 2.5. This discrepancy may be caused by the fact that the ratio of the scattering yield from the regular lattice atom for $\psi / \psi_{1 / 2}=0$ to that for $\psi / \psi_{1 / 2}=2.0$ is overestimated.

In the present experiment, as described previously, the $\mathrm{He}^{+}$ions backscattered between the maximum penetration depth of $1 \mu \mathrm{m}$ and the crystal surface were counted. On the other hand the computer simulation was carried out to the maximum depth of about $0.3 \mu \mathrm{m}$. As well known, the dechanneling caused by atomic electrons and thermally vibrating atoms increases the backscattering yield of $\mathrm{He}^{+}$ions at large penetration depth. Moreover. the interstitial defects and also the alkali and halogen ions displaced due to the presence of the interstitial ion make a considerable contribution on dechanneling [16]-[18]. 


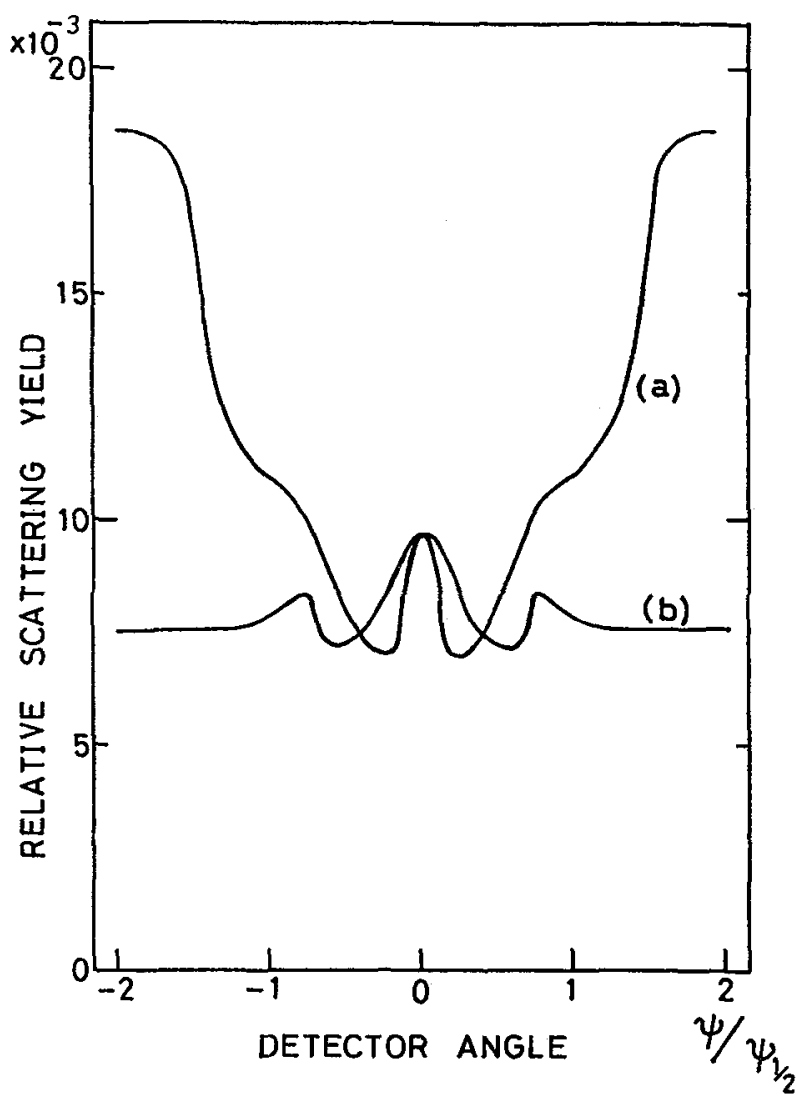

FIG. 5. - Angular dependence around the $\langle 100\rangle$ axis and in the (100) plane of the calculated relative scattering yield of helium ions backscattered from a $\mathrm{KBr}$ crystal containing body-center interstitials at a fractional concentration $5 \times 10^{-3}$ (curve (a)). Experimental angular dependence around $\langle 100\rangle$ axis and in the (100) plane is represented by curve (b). Each yield profile is normalized by the value of the yield at $\psi / \psi_{1 / 2}=0$.

The dechanneling may reduce the relative scattering yield from the lattice ions at the planar direction more predominantly than that at the channeled direction, as described below. In a perfect channel, the yield ratio at the axial direction to the planar direction may be the ratio of the emission yields of particles from thermally vibrating atoms into the axial and planar direction. This ratio has been used to obtain the curve (a) of figure 5. Due to the dechanneling effect only $\left(1-\bar{\chi}_{a}\right)$ of the particles emitted into an axial channel can reach the surface, where $\chi_{a}$ is the average minimum yield over the distance of $0 \sim 1 \mu \mathrm{m}$ for the axial channel. Similarly for the planar channel, the emission yield is reduced by a factor of $\left(1-\bar{\chi}_{p}\right)$, where $\bar{\chi}_{p}$ is the average yield for the planar channel. It follows that the dip for the yield profile shown curve (a) in figure 5 is reduced by a factor of $\left(1-\bar{\chi}_{a}\right) /\left(1-\bar{\chi}_{p}\right)$ due to the dechanneling. $\bar{\chi}_{\mathrm{a}}$ and $\bar{\chi}_{\mathrm{p}}$ were obtained by a backscattering experiment to be $\bar{\chi}_{\mathrm{a}}=0.30, \bar{\chi}_{\mathrm{p}}=0.66$. Thus the dip in the calculated yield profile in figure 5 should become shallower by a factor of 2. This factor is an underestimate, since the channeled particle emitted from an atom near a lattice position possesses high transverse energy, whereas $\bar{\chi}_{\mathbf{a}}$ and $\bar{\chi}_{\mathbf{p}}$ were obtained with a collimated beam.

The other effect which has not been taken into account is the effect of backscattering from the displaced atoms around the interstitial. According to Diller's calculation the distortion of the neighboring ions is as large as $15 \%$ and is nearly along $\langle 111\rangle$ axes for most of the neighboring ions [19]. The incident channeled particles scattered by these distorted atoms produce a yield profile with smaller dip than those scattered by lattice ions. The yield profile caused by the distorted ions should be added to that caused by thermally vibrating atoms shown in figure 5. According to the work by Miyagawa et al. introducing a few per cent of substitutional $\mathrm{Br}$ in $\mathrm{KCl}$ causes a increase of the axial minimum yield by three times of the theoretical minimum yield [20]. In view of the fact that the distortion around the interstitial defects is much larger than that around the substitutional $\mathrm{Br}$, it appears that the distorted lattice around the interstitial $\mathrm{Br}$ molecule of $0.5 \%$ in concentration may flatten considerably the yield profile curve which is obtained for an undistorted lattice.

The half width of the peak of the experimental yield profile around the [100] axis is nearly twice of that of the calculated yield profile for the body-centered position. This discrepancy may be parlty ascribed to that $\mathrm{Br}$ atom does not situate exactly at the body-centered position described above. The other cause of the broadening of the peak may be the dechanneling effect.

The location of the interstitials constituting the $\mathrm{V}_{4}$-center to be near the body-centered position may satisfy both the White's model and Catlow's model. According to the dichroic bleaching measurement, however, the $\mathrm{V}_{4}$-center in $\mathrm{KBr}$ is known to be oriented along a $<100>$ direction [21]. In view of the $\langle 100\rangle$ symmetry of the $V_{4}$-center, the present investigation supports the White's model of the $\mathrm{V}_{4}$ center shown in figure 6 , although a good agreement

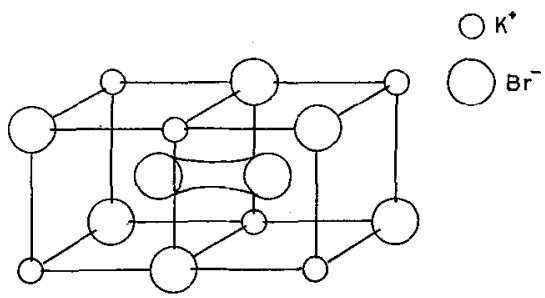

FIG. 6. - A model of the $\mathrm{V}_{4}$-center in $\mathrm{KBr}$ lattice.

has been obtained between theoretical energies of $\mathrm{X}_{3}^{-}$and of $\mathrm{V}_{4}$-center in $\mathrm{KCl}, \mathrm{KBr}$ and $\mathrm{KI}{ }^{1}{ }^{1}$ ). It is also possible that the model of the $\mathrm{V}_{4}$-center may not be so simple as proposed by White and coworker. The $\mathrm{Cl}_{2}$ molecule may form a molecular bonding with the neighboring $\mathrm{Cl}^{-}$ions which are on the crystal plane

(1) Tasker, P. W., private communication. 
intersecting with the molecular axis. According to the White's calculation the distance between $\mathrm{Cl}$ atoms in $\mathrm{Cl}_{2}$ is $1.974 \AA$. This value is smaller than the half of the lattice constant and may explain the broadening of the peak.
Authors are grateful to the member of the Van de Graaff group cooperation. They also express their gratitude to A. M. Stoneham and P. W. Tasker for the valuable discussions concerning to the model of the $\mathrm{V}_{4}$-center.

\section{References}

[1] Sonder, E. and Sibley, W. A., Point Defects in Solids ed. J. H. Crawford, Jr. and L. M. Slifkin (Plenum, New York) (1972) 201.

[2] Fowler, W. B., The Physics of Color Centers, ed.W. B. Fowler (Academic Press, New York) 1968 p. 53 and

Kabler, M. N., Point Defects in Solids, ed. J. H. Crawford, Jr. and L. M. Slifkin (Plenum, New York) 1 (1972) 327.

[3] Ітон, N., Cryst. Lattice Defects 3 (1972) 115.

[4] White, W. W. and Greene, A. C., Cryst. Lattice Defects 1 (1970) 83.

[5] Catlow, C. R. A., Diller, K. M. and Norgett, M. J., J. Phys. C 8 (1975) 134.

[6] Gemmell, D. S., Rev. Mod. Phys. 46 (1974) 129.

[7] Morgan, D. V. (ed), Channeling (John Wiley, New York) 1973.

[8] Feldman, L. C. and Appleton, B. R., Appl. Phys. Lett. 15 (1969) 305 ;

Appleton, B. R. and Feldman, L. C., Atomic Collisions in Solids, ed. D. W. Palmers, M. W. Thompson and P. D. Townsend (North Holland, Amsterdam) 1970, p. 417
[9] Picraux, S. T., Brown, W. L. and Gibson, W. M., Phys. Rev. B 6 (1972) 1382.

[10] Morita, K. and Carstanjen, H. D., Rad. Effects 28 (1976) 97.

[11] MoRITA, K., Rad. Effects 28 (1976) 65.

[12] Kingsley, J. D., J. Phys. \& Chem. Solids 23 (1962) 949.

[13] Andersen, J. U. and Feldman, L. C., Phys. Rev. B 1 (1970) 2063.

[14] Stoneham, A. M., Theory of Defects in Solids (Oxford University Press, London) 1975.

[15] Pooley, D., Brit. J. Appl. Phys. 17 (1966) 855.

[16] BeHRish, R., Ion Beam Surface Layer Analysis, ed. O. Meyer, G. Linker and F. Käppler (Plenum Press New York) 1975.

[17] Matsunami, N. and Iтoh, N., Phys. Lett. 43A (1975) 435.

[18] Matsunami, N., J. Phys. Soc. Japan 38 (1975) 848.

[19] Diller, K. M., Thesis (1975).

[20] Miyagawa, S., Morita, K., Matsunami, N., TachiBANA, K., and ITOH, N., Rad. Effects 13 (1972) 27J and unpublished results.

[21] Ітон, N., J. Phys. \& Chem. Solids 27 (1966) 197.

\section{DISCUSSION}

C. JACCARD. - Do you take flux peaking into account in the calculation of the yield $v s$ angle?

N. IroH. - Yes. In the Monte Carlo calculation, the flux peaking is automatically taken into account. It is indeed due to the flux peaking that the location could be made. 